\title{
World Federation of Critical Care Nurses 2019 Position Statement: Provision of a Critical Care Nursing Workforce
}

Melissa J. BLOOMER, PhD, Crit. Care Cert., BN, RN ${ }^{a, b}$, Paul FULBROOK, RN, PhD, MSc, PGDipEduc, BSc (Hons) ${ }^{c, d, e}$, Sandra GOLDSWORTHY, PhD, CNCC(C), CMSN(C), CCSNE, RN ${ }^{f}$, Sarah L. LIVESAY, DNP, APRN-BC ${ }^{g}$, Marion L. MITCHELL, PhD, Grad Cert (Higher Ed), BN (Hon), RN, FACCCN ${ }^{h}$, Ged WILLIAMS, RN, MHA, LLM, FACN, FAAN ${ }^{i, j}$, and Adriano FRIGANOVIC, MSN, BN, RN ${ }^{k, I}$

Background: Due to changes in critical care worldwide, the World Federation of Critical Care Nurses Board of Directors commissioned a review of its 2005 Declaration of Buenos Aires: Position Statement on the Provision of a Critical Care Nursing Workforce. Aim: To provide international recommendations to inform and assist critical care nursing associations, health services, governments, and other interested stakeholders in the development and provision of an appropriate critical care nursing workforce. Methods: An international review group was established, comprised of critical care nurse clinicians, leaders, and researchers. A literature search was undertaken, which informed the revision of the 2005 Declaration, which is contained in the 2019 Position Statement. Position: The position is supported by six central principles, and is comprised of eight key statements: A critical care unit should have a dedicated nurse leader; Each shift should have at least one registered nurse (RN) designated as the team leader; The majority of $R N$ s providing patient care should hold a recognized post-registration qualification or certification in critical care; Critical care RN staffing should be assessed on a shift-by-shift basis according to patient acuity, the staffing profile, and unit need; An additional critical care $R N$, not counted in $R N$-to-patient ratios or allocated a patient load, may provide additional hands-on assistance in patient care, and coordinate other patient-related activities; Support staff (such as nursing and allied health assistants, nursing aides, and care assistants) should work only under the direct supervision of a critical care $R N$, and never in place of a critical care $R N$; Where institutionally supported, and in accordance with local legislation, a critical care $R N$ may provide expert critical care consultancy; A critical care unit should be staffed to provide at least one senior nurse, who holds a recognized post-registration critical care qualification or certification, and ideally further qualifications in education.

Keywords: critical care; intensive care; nursing; position statement; staffing; workforce; World Federation of Critical Care Nurses

\footnotetext{
${ }^{a}$ Senior Lecturer, School of Nursing and Midwifery, Deakin University, Geelong, Victoria, Australia. E-mail: m.bloomer@deakin.edu.au

${ }^{b}$ Member, Centre for Quality and Patient Safety Research, Deakin University, Geelong, Victoria, Australia

${ }^{c}$ Professor of Nursing, School of Nursing, Midwifery and Paramedicine, Australian Catholic University, Brisbane, Australia

${ }^{d}$ Nursing Director, Nursing Research and Practice Development Centre, The Prince Charles Hospital, Brisbane, Australia

${ }^{e}$ Honorary Professor, Faculty of Health Sciences, University of the Witwatersrand, Johannesburg, South Africa

${ }^{f}$ Associate Professor, Faculty of Nursing, University of Calgary, Calgary, Canada

${ }^{g}$ Associate Professor, Rush University College of Nursing, Chicago, United States

${ }^{h}$ Professor of Critical Care, School of Nursing and Midwifery, Griffith University, Brisbane, Australia; Nursing Practice Development Unit, Princess Alexandra Hospital, Woolloongabba, Australia

${ }^{i}$ Adjunct Professor, School of Nursing and Midwifery, Griffith University, Brisbane, Australia

${ }^{j}$ Chief Nursing Officer, Mafraq Hospital, Abu Dhabi, United Arab Emirates

${ }^{k}$ Senior Lecturer, University of Applied Health Sciences, Zagreb, Croatia

${ }^{1}$ Head Nurse, University Hospital Centre, Zagreb, Croatia
} 


\section{INTRODUCTION}

The Position Statement on the Provision of a Critical Care Nursing Workforce was first released in 2005 as the Declaration of Buenos Aires (Williams, Schmollgruber, \& Alberto, 2006; World Federation of Critical Care Nurses, 2005), with the aim to inform and assist critical care nursing associations, health services, governments, and other interested stakeholders in the development and provision of an appropriate critical care nursing workforce. Due to changes in critical care worldwide, the World Federation of Critical Care Nurses (WFCCN) Board of Directors commissioned a review of the 2005 Declaration. As a result of this review, revisions were undertaken. This document represents the 2019 revised Position Statement: Provision of a Critical Care Nursing Workforce.

The objective of the WFCCN review group was to review and update the existing Declaration of Buenos Aires. The aim of the revised Position Statement is consistent with the original Declaration:

to provide international recommendations to inform and assist critical care nursing associations, health services, governments and other interested stakeholders in the development and provision of an appropriate critical care nursing workforce.

\section{Critical Care Nursing Workforce}

Critical care is a term used typically to encompass a range of care settings including intensive care, high dependency care, and coronary care units (Fulbrook, 2010). Critical care is a complex and growing area of specialty practice (Dury et al., 2014; Williams et al., 2012), developed to serve the diverse healthcare needs of patients with actual or potential life-threatening conditions, and their families. Patients receiving critical care typically have highly complex needs and receive multiple therapies to address multiple problems (Coombs \& Lattimer, 2007), made possible by rapidly evolving scientific and technological advances.
In order to manage the intellectual, physical, psychosocial, cultural, and ethical challenges inherent in the provision of critical care, the provision of an appropriate critical care nursing workforce requires careful planning and execution to ensure a balance of skills and expertise to ensure safe and high-quality patient care (Kleinpell, 2014). It is essential that all registered nurses (RNs) (International Council of Nurses, 2019) in critical care settings are adequately equipped, both practically and theoretically (Labeau, Chiche, \& Blot, 2012), to respond to clinical changes without compromising care.

Optimal staffing ratios have been the subject of much international debate, yet consensus exists to support the need for specified minimum RN-to-patient ratios (Chamberlain, Pollock, Fulbrook, \& ACCCN Workforce Standards Development Group, 2018; New Zealand College of Critical Care Nurses, 2015). Whilet it was already known that patient outcomes were better in settings with higher RN-to-patient ratios (Rafferty et al., 2007), more recent critical care research evidence demonstrates that higher numbers of RNs per bed are associated with better patient survival rates (West et al., 2014), and a reduced risk of ventilator-associated pneumonia (Blot et al., 2011). Furthermore, a higher ratio of RNs with specialized critical care training has been shown to result in better patient outcomes (Blake, 2013). Critical care RNs also commonly contribute to rapid response systems or teams, established to extend critical care services to other hospital areas (Jung et al., 2016). Where established, rapid response teams are associated with a significant decrease in unexpected and overall mortality for inpatients (Jung et al., 2016). Increased nursing requirements and additional roles should be factored into RN staffing within critical care units to enable such service provision (New Zealand College of Critical Care Nurses, 2015). Furthermore, consideration should be given to the qualifications, skills, experience, and attributes of nursing staff, acknowledging that patient care needs may necessitate a reevaluation of staffing requirements (Blake, 2013; Chamberlain 
et al., 2018; New Zealand College of Critical Care Nurses, 2015).

It is imperative that governments, hospital boards, educational providers, and professional bodies recognize that the future of critical care nursing calls for RNs to be viewed as highly skilled and educated partners in the provision of high-quality healthcare (Barnhorst, Martinez, \& Gershengorn, 2015). This recognition begins with acknowledging the importance of critical care RNs having access to education programs that aid the development and advancement of skills and expertise in critical care nursing, irrespective of seniority or geographic location (Endacott et al., 2015; Hendrickx \& Winters, 2017). Educational opportunities should encompass bedside education, to ensure the health and safety of vulnerable patients and improve longterm organizational efficiency in critical care (Chamberlain et al., 2018; Labeau et al., 2012).

\section{METHODS}

Following establishment of a review group comprised of critical care clinicians, leaders and researchers, a literature search was undertaken, which informed the review of the 2005 Declaration and its subsequent revision contained in this 2019 Position Statement. Several drafts were reviewed and revised, culminating in international discussions about the purpose and content. A final draft, comprised of central principles and recommendations, was presented at the 13th WFCCN Congress in Belgrade, Serbia, in October 2018, where professional consultation was invited. Subsequent to this meeting, this revised Position Statement was approved by the WFCCN Board of Directors on 22 March 2019.

\section{POSITION STATEMENT: PROVISION OF A CRITICAL CARE NURSING WORKFORCE \\ Central Principles}

1. Every patient should be cared for in an environment that best meets their individual needs.

2. It is a patient's right to be cared for by appropriately educated and skilled RNs.
3. At all times, there should be congruence between the needs of each patient and the skills, knowledge and attributes of the nurse caring for the patient.

4. Critical care units should aim for high RN-to-patient ratios, such as a 1:1 ratio for unconscious and ventilated patients, and lesser for high dependency patients. Critical care $\mathrm{RN}$ staffing should reflect patient acuity and should be assessed on a case-by-case basis.

5. Flexible workforce strategies and incentives should be utilized to support the recruitment, retention, and remuneration of all critical care RNs, regardless of position or experience, and should ensure appropriate succession planning for future leadership needs.

6. Critical care nurses should focus on tasks that require expert or advanced skill, expertise, and knowledge of best practice in patient care. Therefore, consideration of various staffing models, utilizing support staff, should be considered to prioritize critical care RNs for specialist patient care.

\section{WFCCN Position}

1. A critical care unit should have a dedicated nurse leader

- The nurse leader (also referred to as charge nurse; director; head nurse; nurse unit manager; or similar) should manage and lead the nursing staff of the critical care unit.

- The nurse leader should have a recognized post-registration critical care qualification with significant clinical and leadership experience, and ideally, a management or leadership qualification.

\section{Each shift should have at least one RN} designated as the team leader

- The team leader (also referred to as clinical coordinator; nurse-in-charge; or similar) should provide leadership 
and supervision and provide direction to the team throughout each shift.

- Team leaders should have critical care training and should be senior and experienced RNs with appropriate expertise to lead the clinical team.

3. The majority of RNs providing patient care should hold a recognized postregistration qualification or certification in critical care

- All other RNs are expected to work toward a post-registration qualification or certification in critical care.

4. Critical care RN staffing should be assessed on a shift-by-shift basis according to patient acuity, the staffing profile, and unit need

- At times, some patients with more complex needs, for example, postorgan transplantation, or those receiving complex therapies such as extracorporeal membrane oxygenation or ventricular assist devices, may require more than one critical care RN.

5. An additional critical care RN, not counted in RN-to-patient ratios or allocated a patient load, may provide additional hands-on assistance in patient care, as well as coordinate other patientrelated activities

- Ideally, this RN should have a recognized post-registration critical care qualification or certification and possess significant clinical experience.

6. Support staff (such as nursing and allied health assistants, nursing aides, and care assistants) should work only under the direct supervision of a critical care $R N$, and never in place of a critical care $R \boldsymbol{N}$

- Support staff are addition to the abovementioned RN-to-patient ratios.

7. Where institutionally supported, and in accordance with local legislation, a critical care RN may provide expert critical care consultancy

- Consultancy may include the assessment, stabilization, and management of critically ill and unstable patients within the hospital, and may include participation in rapid response or medical emergency teams.

8. A critical care unit should be staffed to provide at least one senior nurse, who holds a recognized post-registration critical care qualification or certification, and ideally further qualifications in education

- Working in collaboration with the nurse leader, this nurse (who may be known as an educator) should provide an orientation program for all new staff, and ongoing educational support to all RNs, based on identified individual needs.

\section{References}

Barnhorst, A. B., Martinez, M., \& Gershengorn, H. B. (2015). Quality improvement strategies for critical care nursing. American Journal of Critical Care, 24(1), 87-92.

Blake, N. (2013). Appropriate staffing for a healthy work environment. AACN Advanced Critical Care, 24(3), 245-248.

Blot, S. I., Serra, M. L., Koulenti, D., Lisboa, T., Deja, M., \& Myrianthefs, P. (2011). Patient to nurse ratio and risk of ventilator-associated pneumonia in critically ill patients. American Journal of Critical Care, 2O(1), e1-e9.

Chamberlain, D., Pollock, W., \& Fulbrook, P. (2018). ACCCN workforce standards for intensive care nursing: Systematic and evidence review, development, and appraisal. Australian Critical Care, 31(5), 295-302.

Coombs, M., \& Lattimer, V. (2007). Safety, effectiveness and costs of different models of organising care for critically ill patients: Literature review. International Journal of Nursing Studies, 44(1), 115-129. 
Dury, C., Hall, C., Danan, J. L., Mondoux, J., Aguiar Barbieri-Figueiredo, M. C., Costa, M. A., \& Debout, C. (2014). Specialist nurse in Europe: Education, regulation and role. International Nursing Review, 61(4), 454-462.

Endacott, R., Jones, C., Bloomer, M. J., Boulanger, C., Ben Nun, M., Lliopoulou, K. K., . . . Blot, S. (2015). The state of critical care nursing education in Europe: An international survey. Intensive Care Medicine, 41(12), 2237-2240.

Fulbrook, P. (2010). Critical care or intensive care? Connect: The World of Critical Care Nursing, 7(2), 107.

Hendrickx, L., \& Winters, C. (2017). Access to continuing education for critical care nurses in rural or remote settings. Critical Care Nurse, 37(2), 66-71.

International Council of Nurses. (2019). Nursing Definitions. Retrieved from https://www. icn.ch/nursing-policy/nursing-definitions

Jung, B., Daurat, A., De Jong, A., Chanques, G., Mahul, M., Monnin, M., . . Jaber, S. (2016). Rapid response team and hospital mortality in hospitalized patients. Intensive Care Medicine, 42(4), 494-504.

Kleinpell, R. M. (2014). ICU workforce: Revisiting nurse staffing. Critical Care Medicine, 42(5), 1291-1292.

Labeau, S., Chiche, J. D., \& Blot, S. (2012). Postregistration ICU nurses education: Plea for a European curriculum. International Journal of Nursing Studies, 49(2), 127-128.

New Zealand College of Critical Care Nurses. (2015). New Zealand standards for critical care nurse staffing. Retrieved from https:// www.nzno.org.nz/Portals/O/Files/Documents/ Groups/Critical\%20Care\%20Nurses/20150922 \%2ONZStandards\%20for\%20CC\%20Nursing\%20 final.pdf

Rafferty, A. M., Clarke, S. P., Coles, J., Ball, J., James, P., McKee, M., \& Aiken, L. H. (2007). Outcomes of variation in hospital nurse staffing in English hospitals: Crosssectional analysis of survey data and discharge records. International Journal of Nursing Studies, 44(2), 175-182.

West, E., Barron, D. N., Harrison, D., Rafferty, A. M., Rowan, K., \& Sanderson, C. (2014). Nurse staffing, medical staffing and mortality in intensive care: An observational study. International Journal of Nursing Studies, 51(5), 781-794.

Williams, G., Bost, N., Chaboyer, W., Fulbrook, P., Alberto, L., Thorsteinsdóttir, R., . . Chan, D. (2012). Critical care nursing organizations and activities: A third worldwide review. International Nursing Review, 59(1), 73-80.

Williams, G., Schmollgruber, S., \& Alberto, L. (2006). Consensus forum: Worldwide guidelines on the critical care nursing workforce and education standards. Critical Care Clinics, 22(3), 393-406.

World Federation of Critical Care Nurses. (2005). Position statement on the provision of critical care nursing workforce - Declaration of Buenos Aires, 2005. Retrieved from http://wfccn.org/wp-content/uploads/ 2018/01/BuenoAires-declarations.pdf

Acknowledgments. The following colleagues are acknowledged for their contribution to the review and revision of the position statement: Leanne Aitken, United Kingdom; Eva Barkestad, Sweden; Nicola Credland, United Kingdom; Rossana Gonzales De la Cruz, Peru; Susan Yeager, United States; Pauline Wong, Australia.

Disclosure. The authors have no relevant financial interest or affiliations with any commercial interests related to the subjects discussed within this article. 